\title{
Mitos e nós do agronegócio no Brasil
}

Denise Elias

Universidade Estadual do Ceará. Centro de Ciências

e Tecnologia. Fortaleza. Ceará. Brasil deniseliasgeo@gmail.com

(D) 0000-0002-8384-0990

\section{revista}

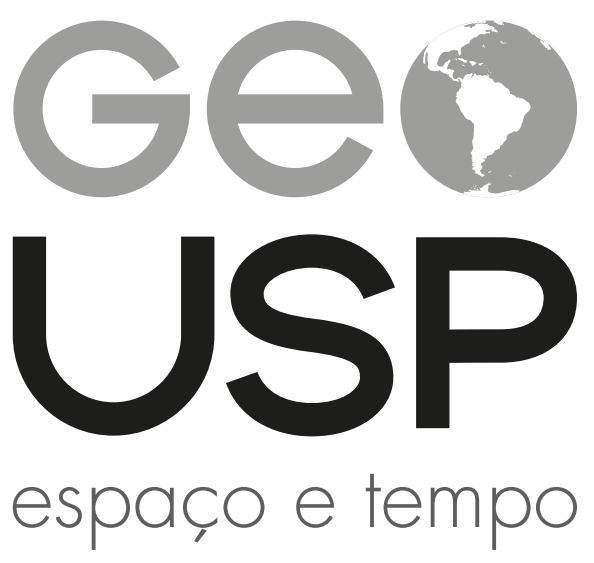

Volume $25 \bullet n^{\circ} 2(2021)$

ISSN 2179-0892 e-182640

Como citar este artigo:

ELIAS, D. Mitos e nós do agronegócio no Brasil. Geousp, v. 25, n. 2, e-182640, ago. 2021. ISSN 2179-0892.

Disponivel em: https://www.revistas.usp.br/geousp/article/ view/182640. doi: https://doi.org/10.11606/issn.2179-0892. geousp.2021.182640.

\section{(c) (i)}

Este artigo está licenciado sob a Creative Commons Attribution 4.0 Licence 


\title{
Mitos e nós do agronegócio no Brasil
}

\section{Resumo}

O presente artigo parte da hipótese de que os retrocessos políticos vividos no Brasil desde o golpe parlamentar de 2016 mostram a tendência ao aumento de poder dos agentes hegemônicos do agronegócio atuantes no país e, consequentemente, a propensão ao agravamento das desigualdades socioespaciais, dos conflitos e da violência no campo e nas cidades. $O$ principal objetivo é discutir o que consideramos alguns dos principais mitos e nós nos quais se escora o agronegócio, uma vez que julgamos que devem ser desfeitos para que possamos trilhar os caminhos para uma sociedade mais justa, igualitária e democrática. A metodologia estruturou-se nos fundamentos da pesquisa qualitativa. Concluímos que as formas-conteúdo do agronegócio são contestáveis e devem ser rejeitadas e substituídas por outras.

Palavras-chave: Retrocesso político. Agronegócio. Bancada Ruralista. Brasil.

\section{Myths and knots of agribusiness in Brazil}

\begin{abstract}
The concept of this article starts from the hypothesis that since 2016's coup d'etat in Brazil political setbacks tend to increase the power of agribusiness hegemonic agents in the country. As a result, urban and rural social-spatial inequalities, conflicts and violence tend to worsen. The main objective is to discuss what is regarded as most supportive myths and nodes of agribusiness. That way, we assume such nodes and myths should be untied and undone, allowing us to tread the path to a fairer, more democratic and egalitarian society. The methodology is based upon qualitative research. As a conclusion, agribusiness "content-shapes" are dubious and should be refused, in order to be replaced by other ones.
\end{abstract}

Keywords: Political setbacks. Agribusiness. Ruralist bench. Brazil. 


\section{Mythes et nceud de l'agrobusiness au Brésil}

\section{Résumé}

La rédaction du présent article trouve son origine dans l'hypothèse voulant que les régressions politiques vécues au Brésil depuis le coup parlementaire de 2016 montrent la tendance de l'augmentation des pouvoirs des agents hégémoniques de l'agrobusiness en activité dans le pays et, par conséquent, la propension à l' explosion des inégalités sociales et territoriales, des conflits et de la violence à la campagne et dans les villes. L'objectif principal est d'aborder ce que nous comprenons comme étant certains des principaux mythes et nceuds s'appuyant sur l'agrobusiness, étant entendu que nous jugeons qu'ils demandent à être déconstruits afin que nous puissions tracer le chemin d'une société plus juste, égalitaire et démocratique. La méthodologie s' est structurée autour des fondements de la recherche qualitative. Nous concluons que les formes-contenu de l'agrobusiness sont contestables et doivent être refusées et remplacées par d'autres.

Mots-clés: Régression politique. Agrobusiness. Lobbying rural. Brésil.

\section{Introdução}

A concepção do presente artigo parte da hipótese principal de que os retrocessos políticos vivenciados no Brasil desde o golpe parlamentar de 2016, que escancaram as portas para o grande capital privado, mostram a tendência ao aumento de poder dos agentes hegemônicos do agronegócio atuantes no país e, consequentemente, a propensão ao acirramento das desigualdades socioespaciais, dos conflitos e da violência no campo e nas cidades.

Desde esse momento de inflexão na política, muitos dos direitos conquistados depois de décadas de luta pela sociedade vêm sendo negociados num enorme balcão de negociatas iniciados no mandato do presidente Michel Temer (31/08/2016-31/10/2018), para se manter no poder, processo acirrado com a posse do presidente Jair Messias Bolsonaro (01/01/2019-), com o apoio das elites econômica, política, jurídica e dos militares das Forças Armadas ao conjunto de reformas perversas.

Estamos vivenciando um desmonte das políticas públicas compensatórias que, de alguma maneira, protegiam setores e categorias sociais mais vulneráveis. Verdadeiras atrocidades vêm sendo impostas a toda a sociedade, tais como o congelamento dos gastos públicos por 20 anos, a reforma trabalhista representando a supressão de direitos, que deixa em ruínas a Consolidação das Leis do Trabalho (CLT), marco legal que estabelece normas regulatórias de relações individuais e coletivas de trabalho no Brasil, um conjunto de privatizações e concessões nas áreas de energia, mineração e petróleo, portos e aeroportos, entre outros, altíssimos percentuais de cortes dos gastos 
públicos com ciência, tecnologia e inovação, ${ }^{1}$ extinção do Ministério de Desenvolvimento Agrário (MDA), estrangulamento de recursos para programas como o Programa de Aquisição Alimentos da Agricultura Familiar e reduções radicais do orçamento para programas de segurança alimentar, reforma agrária, fortalecimento da agricultura familiar, entre tantos outros.

Tudo isso vem acompanhado do acirramento da crise econômica, do avanço do desemprego e da precarização das condições gerais de trabalho, do enfraquecimento e da desarticulação dos sindicatos, da debilitação de muitos movimentos sociais, da dilapidação do poder de compra da população e da crise das esquerdas. Se não bastassem todos os colapsos supracitados, desde o começo de 2020, vivemos a pandemia da Covid-19, representando uma condição de descaminho para todo o mundo, cujas consequências ainda não podemos prever na sua totalidade. ${ }^{2}$

Em contrapartida, assistimos ao aumento do poder da Frente Parlamentar da Agropecuária (FPA) no Congresso Nacional, mais conhecida como a bancada ruralista (BR), um lobby financiado por associações e empresas do agronegócio, claramente uma das principais fiadoras do governo do presidente Jair Bolsonaro. As evidências são muitas, o que reforça a hipótese que dá mote ao artigo.

Desde o período considerado para análise, a Casa Civil já suspendeu mais de uma dezena de processos de demarcação de terras indígenas que só aguardavam homologação presidencial. $\bigcirc$ ex-presidente Temer endossou um parecer da Advocacia Geral da União (AGU) que proibiu reconhecer como área indígena qualquer reserva que tenha se formado depois da Constituição de 1988. O desmonte da Fundação Nacional do Índio (Funai) segue a passos largos com suspensões de recursos e loteamento de cargos, até mesmo de escalões essencialmente técnicos, por pessoas sem capacitação adequada. ${ }^{3} \bigcirc$ número de liberações de agrotóxicos para uso em lavouras alcançou uma soma nunca antes conhecida para um intervalo igual, autorizando um conjunto de produtos proibidos em outros países por representar sérios riscos à saúde da população e ao meio ambiente. A violência no campo, traço estruturante da sociedade brasileira, aumentou e pode ser comprovada pelo crescimento do número de assassinatos de indígenas e de disputas por terra e por água.

Por outro lado, o número de queimadas e desmatamentos criminosos em 2019 e 2020 bateu todos os recordes, tendo consumido percentuais significativos de alguns dos mais importantes biomas brasileiros, especialmente a Amazônia e o Pantanal. Contudo, até o momento os responsáveis seguem impunes como mais uma prova do desmonte das políticas ambientais sob a batuta do ministro do Meio Ambiente Ricardo Salles (2019-). Não esqueçamos da sua funesta declaração por ocasião da fatídica reunião ministerial com o presidente Jair Bolsonaro, no dia 22 de abril de 2020, quando defende que o momento seria oportuno para aproveitar a

1 Como os que ocorrem no CNPq, a maior agência de fomento à pesquisa do Brasil, que há décadas tem um papel primordial na formulação e na condução de políticas de ciência, tecnologia e inovação no país, comprometendo o desenvolvimento da ciência brasileira e, por fim, da própria soberania do Brasil. Mais informações sobre o tema podem ser vistos em Elias (2020a).

2 No momento em que terminamos este artigo, em 9 de fevereiro de 2021, o mundo já contabilizou mais de 2,3 milhões de mortes pela Covid-19, somando o Brasil o segundo maior contingente, com 231.534 vidas perdidas, número superado apenas pelos 464.921 mortos nos EUA (Google, [s.d.]).

3 O blogue Outras Mídias publicou matéria sobre o impacto da gestão atual na Funai (Souza, 2019). 
"tranquilidade da cobertura da imprensa", com atenção voltada para a pandemia da Covid-19, para "passar a boiada" e aprovar desregulamentações ambientais. ${ }^{4}$

Ademais, o tecido social no país está totalmente esgarçado e a exclusão de milhões de brasileiros, o patrimonialismo e a manutenção da cultura do privilégio determinam como as relações sociais se processam no Brasil, inibindo a construção de relações de reciprocidade e de uma sociedade de direitos. Isso reflete em situações que temos vivenciado em nosso cotidiano, como tensão social, violência e banalização da vida humana.

Diante do exposto, entendemos que os pilares que sustentam o agronegócio brasileiro representam um entrave para avançarmos na construção da emancipação social e de uma sociedade mais democrática. $\bigcirc$ artigo apresenta o que inferimos como alguns dos principais mitos e nós que escoram o agronegócio, uma vez que julgamos que demandam ser desfeitos e desatados para que possamos trilhar os caminhos dessa outra sociedade.

$\bigcirc$ método científico permite, a partir da análise de uma totalidade, realizar esforços de caracterização e de síntese. Como o agronegócio brasileiro da forma como o conhecemos hoje está em construção há cinco décadas, notadamente desde os anos 1970, balizamo-nos na realidade concreta e em um conjunto de pesquisas e estudos científicos, incluindo os de autoria própria, para trazer as interpretações apresentadas aqui.

A metodologia estruturou-se nos fundamentos da pesquisa qualitativa para a construção de uma análise crítica. Assim, privilegiamos a pesquisa bibliográfica e documental. Por outro lado, um dos principais procedimentos metodológicos foi construir uma hemeroteca segundo temas e processos de interesse. Além de trabalhos acadêmicos como livros, teses, dissertações e artigos científicos, consultamos jornais, revistas especializadas e uma gama de matérias das chamadas novas mídias, que podem ser acessadas diretamente pela internet. ${ }^{5}$ Os trabalhos de campo realizados em diferentes momentos nas últimas décadas, em diversas áreas de difusão do agronegócio do Brasil, foram também inestimáveis para algumas das interpretações apresentadas.

Além desta introdução e das considerações finais, o artigo tem quatro seções. Na primeira, discutimos os pressupostos principais do agronegócio brasileiro, apresentando um conjunto de características inerentes a ele, considerando agentes e dinâmicas socioespaciais. Na segunda, discorremos sobre alguns dos principais mitos que sustentam o agronegócio, terminando com o que consideramos os nós do agronegócio que precisam ser desatados para a construção de uma sociedade mais igualitária no país. Na terceira e quarta seções, abordamos dois dos nós do agronegócio que precisam rapidamente ser desatados, quais sejam, o nó da relação orgânica entre o Estado e agentes do agronegócio e o nó da criminalização dos movimentos sociais.

4 A declaração do ministro do Meio Ambiente tinha como objetivo alertar os participantes da reunião ministerial do que considerava uma oportunidade ensejada pela pandemia da Covid-19, qual seja, mudar leis ambientais que poderiam ser questionadas na Justiça, enquanto a sociedade e a mídia estavam voltadas para a pandemia (Ministro do Meio Ambiente..., 2020). A divulgação foi autorizada pelo então ministro do Supremo Tribunal Federal (Ministro Celso de Mello..., 2020).

5 Entre as quais destacamos De Olho nos Ruralistas, Brasil de Fato, Outras Mídias, Carta Capital, Repórter Brasil, Diário do Centro do Mundo, Outras Palavras, Nexo Jornal, Le Monde Diplomatique Brasil, Mídia Ninja e A Terra é Redonda e o ranking de grandes empresas publicados por revistas e jornais de circulação nacional como Exame Melhores e Maiores, Valor 1000 Maiores Empresas, Globo Rural, Dinheiro Rural e Forbes. 


\section{Pressupostos do agronegócio}

Mesmo que brevemente, é importante destacar o que consideramos alguns dos principais pressupostos do agronegócio. Até mesmo porque, embora hoje se use indiscriminadamente a palavra agronegócio, só há pouco mais de duas décadas ela passou a ter uso corrente no Brasil. Mas, apesar de sua pouca idade, já tem caráter polissêmico, carregada de ideologias e mitos. Isso reforça a necessidade de apresentarmos elementos de argumentação em direção a uma visão crítica sobre o tema. Como a própria palavra deixa explícito (agro + negócio), entre os maiores objetivos está a obtenção de lucro e renda da terra, com a produção de muitas novas mercadorias voltadas ao mercado urbano, nacional e internacional, de alimentos processados e ultraprocessados, de commodities e de agrocombustíveis. ${ }^{6}$

$\bigcirc$ agronegócio abrange um conjunto de atividades que se realizam de forma totalmente interligada. A agropecuária se dá conectada a indústrias (agroindústrias, de máquinas agrícolas, de agrotóxicos, de sementes transgênicas), serviços (centros de pesquisa e experimentação, aviação agrícola, informatização dos processos de produção), comércio especializado no consumo produtivo do agronegócio (ração, implementos agrícolas, fertilizantes), agentes financeiros (bancos, bolsa de valores, fundos de investimento), armazenamento, marketing, logística e distribuição, especialmente em supermercados (Elias, 2003).

De modo geral, o agronegócio se realiza adotando pacotes tecnológicos intensivos em capital e tecnologia (conjunto de insumos químicos, mecânicos e biotecnológicos), que transformam os sistemas técnicos agrícolas e difundem um padrão estandardizado de produção. Por outro lado, é regulado por relações de produção, distribuição e consumo globalizadas calcadas em corporações transnacionais e movimentam grandes volumes de créditos estatais e um conjunto de outras políticas públicas. Além disso, articula um conjunto portentoso de interesses econômicos e políticos, como provam o tamanho e o poder da BR no Congresso Nacional (Elias, 2013).

Para desvelar os mitos e os nós do agronegócio, é importante saber que eles têm nome e endereço, ou seja, conhecer seus agentes hegemônicos. Segundo Oliveira (2016), a agricultura sob o capitalismo mundializado estrutura-se, em especial, a partir da formação de empresas monopolistas, que controlam a produção e se articulam por meio de dois processos monopolistas territoriais no comando da produção agropecuária e florestal mundial: a territorialização dos monopólios e a monopolização do território.

Entre essas empresas monopolistas, há corporações multinacionais atuantes na produção agropecuária e agroindustrial como de laticínios, massas, carnes, biscoitos, alimentos ultraprocessados (Nestlé, Unilever, Danone, M. Dias Branco), agroquímicas (Bayer, Basf, Dupont, Syngenta), fumageiras (Philip Morris, Souza Cruz), tradings (Bunge, Cargill, ADM, Luis Dreyfus), frigoríficos de frango (BRF, JBS, Aurora, Copacol, Globoaves), redes de supermercados (Carrefour, GPA, Cencosud, SDB Comércio de Alimentos Ltda., Irmãos Muffato, Grupo Big) e empresas do sistema financeiro por meio de vários de seus instrumentos, incluindo os fundos de investimentos e

6 Esse debate se iniciou nos EUA na década de 1950, com John Davis e Ray Goldberg, que passaram a adotar e discutir a noção de agribusiness, que envolveria, além da própria atividade agropecuária, todos os setores associados a montante e a jusante dessa atividade. Com desdobramentos em vários outros países, no Brasil, o debate foi intenso, especialmente nas décadas de 1980-90, com vários autores discutindo o que chamavam de complexos agroindustriais (CAI) (Sorj, 1980; Muller, 1989; Silva, J., 1996; Mazzali, 2000) e outros de sistemas agroindustriais (SAG) (Farina; Zylbersztain, 1998). 
títulos de renda fixa (tais como a Letra de Crédito do Agronegócio do Banco do Brasil), com fortíssimo crescimento da financeirização no setor. Devemos considerar também, entre os principais agentes do agronegócio, os grandes proprietários de terra e o Estado.

Essas corporações notabilizam-se pela grande capacidade produtiva instalada, pela complexidade das operações, pelo volume de matéria-prima que processam, pela diversidade de suas atividades econômicas, pelo poder de impor suas demandas ao Estado (logística, incentivos fiscais), pela atuação em diferentes escalas geográficas e pelo controle de grandes áreas de terra, às vezes não só no campo, mas também em cidades (Santos, M., 1979; Corrêa, 2002; Oliveira, 2016; Dowbor, 2017).

Isso já evidencia que o agronegócio não se realiza apenas no campo, mas integrado ao espaço e à economia de diferentes extratos na rede urbana. Além disso, requer relações complexas e permanentes com cidades, de diversos tipos e tamanhos, extrapolando a escala do lugar, da região ou do país (Elias, 2003, 2017a, 2017b, 2020b). O agronegócio envolve desde áreas de produção agropecuária propriamente ditas, até os fixos e fluxos (Santos, M., 1988), sistemas de objetos e sistemas de ação (Santos, M., 1996) associados, distribuídos por muitos países em várias partes do planeta. Assim, além de intersetoriais, os estudos sobre o tema devem ser também multiescalares.

Ricardo Antunes (2016) destacou que, em sua fase atual, o capitalismo ancora-se num tripé destrutivo baseado na reestruturação produtiva e no neoliberalismo, sob o comando do capital financeiro (informação verbal). ${ }^{7}$ Consideramos que é nesse mesmo tripé que estão ancoradas as metamorfoses da atividade agropecuária brasileira das últimas décadas, as quais culminam no que hoje se convencionou chamar de agronegócio globalizado (Elias, 2017a). Assim, as transformações neoliberais na agricultura e no espaço agrário brasileiros têm resultado em muitas ressignificações e conflitos.

De maneira geral, o agronegócio brasileiro se caracteriza por ser espacialmente seletivo, socialmente excludente, economicamente concentrador e ambientalmente e culturalmente devastador. Da mesma forma, sua difusão tem aumentado os níveis de riqueza, cada vez mais concentrados, e os níveis de pobreza, cada vez mais generalizados, além de criar muitas novas e complexas desigualdades socioespaciais, com o aumento dos conflitos e da violência no campo e nas cidades (Elias, 2002, 2006; Elias; Pequeno, 2007, 2015). ${ }^{8}$

São vários os processos que ilustram o que citamos como síntese, e parece-nos importante mostrar alguns que são estruturais. Procuramos abordá-los no que chamamos de nós do agronegócio.

\section{Mitos do agronegócio}

Alguns dos pilares estruturais do modo de produção dominante são a expropriação dos meios de produção e a alienação. Para manter o status quo, é necessária uma ideologia dominante e, como ensina a filósofa Marilena Chauí (1981), a ideologia é um mascaramento da realidade social que permite legitimar a exploração e a dominação e por meio da qual tomamos o falso

7 Informação fornecida por Ricardo Antunes durante um pequeno evento científico ocorrido na PUC-Rio, em outubro de 2016.

8 Na subárea do conhecimento da Geografia Agrária brasileira, há um número grande de pesquisadores, laboratórios, grupos e redes de pesquisa que desenvolvem importantes estudos que trabalham diretamente com esses temas e muito ajudam a compreender aspectos diversos de tal realidade. 
por verdadeiro, o injusto por justo. Assim, a expansão do agronegócio e a perpetuação das desigualdades social, econômica e espacial dele resultantes exigem uma ideologia que as sustente.

É nesse sentido que afirmamos que o agronegócio é cercado de mitos que fabricam um imaginário social favorável a ele. Entre os muitos mitos criados e mais difundidos associados ao agronegócio, há o de que ele é a redenção do Brasil, a locomotiva do país, promove distribuição de renda e desenvolvimento regional, é ambientalmente sustentável e responsável pela segurança alimentar e pela soberania nacional, o mito de que é independente do Estado, de que os agrotóxicos não prejudicam a saúde do homem ou do meio ambiente, o de que o modelo do agronegócio é o único possível no Brasil e o de que as empresas do agronegócio estão entre as mais sustentáveis do país, entre tantos outros.

Corporações e entidades de classe do agronegócio capitaneiam a construção e difusão desses mitos. Para isso, contam com um amplo amparo das empresas da indústria cultural, assim como com a aquiescência do Estado, seja ativa ou passivamente, quando, por exemplo, não cumpre seu papel de regular e fiscalizar em prol do bem comum. Discutindo a sociedade do espetáculo, Debord (2003) nos ajuda a compreender alguns dos mitos sobre o agronegócio na sociedade brasileira, porque, para a produção, difusão e hegemonia do agronegócio, é preciso construir-lhe uma imagem favorável. Assim, para a expansão do capitalismo no campo e a multiplicação da produção de mercadorias que o sustenta, não basta expulsar e expropriar os camponeses, as quebradeiras de coco, os ribeirinhos, os geraiseiros... é também basilar a alienação associada ao agronegócio, a construção de uma psicosfera do agronegócio (Santos, M., 1996).

Vários agentes da indústria cultural brasileira concorrem para tal objetivo, e há muitos exemplos da construção desse caminho nas últimas décadas. Mas, indubitavelmente, poucos tiveram o alcance e lograram tanto êxito como a gigantesca operação publicitária empreendida pela Rede Globo de Televisão, principal canal aberto de televisão do Brasil, pertencente ao Grupo Globo, a maior corporação de mídia e comunicação da América Latina e uma das maiores do mundo, que ocupava a $19^{\circ}$ posição no ranking dos maiores conglomerados de mídia do mundo (Grupo Globo, [s.d.]). Intitulada o "Agro é Tech, Agro é Pop, Agro é tudo", a campanha foi lançada em meados de 2016 e vigora até o momento. É muito dinâmica, pois está no ar ininterruptamente e desde então lança novos temas periodicamente, cada qual tratando de um conjunto de atividades associadas a um produto específico - frango, cana-de-açúcar, café, milho, laranja, melão, abacate, maçã etc.

A sociedade do espetáculo e a criação de mitos do agronegócio estão mais presentes do que nunca, desde a criação dessa campanha, com seu slogan repetido exaustivamente, inúmeras vezes ao dia, a milhões de brasileiros nos intervalos comerciais da emissora, notadamente em seus horários considerados nobres, ou seja, os de maior audiência. É importante lembrar ainda que no Brasil poucos grupos concentram a maior parte da audiência nacional da televisão aberta, o meio de comunicação mais comum no país (A hegemonia..., [s.d.]), o que atesta o alcance da campanha.

Sem dúvida nenhuma, essa campanha da Rede Globo é um marco estruturante para qualquer periodização, elemento fundamental do método científico (Santos, M., 1985, 1988, 1996), que se queira fazer da relação entre o agronegócio e a mídia brasileira visando construir uma imagem positiva do primeiro. Isso tornou mais sólido o papel da Rede Globo de Televisão como uma das responsáveis pela difusão de vários dos mitos do agronegócio brasileiro, muitos 
dos quais foram intensamente fortalecidos, tais como o de que o agronegócio é um modelo de negócio de êxito e o melhor para o campo brasileiro.

Vale mencionar que, de acordo com dados levantados pela ONG Repórteres Sem Fronteira e pelo Coletivo Intervozes sobre a concentração midiática no Brasil, a própria emissora pertence a uma corporação que atua em segmentos do agronegócio, assim como é uma importante proprietária de terras, o que reforça a compreensão da citada campanha publicitária, pois a ela própria interessa difundir uma imagem positiva do agronegócio. ${ }^{9}$ Então, para o caso, não é só uma questão de dizer que o Grupo Globo atua de mãos dadas com os agentes do agronegócio, visto que ele próprio pode ser classificado como um deles. ${ }^{10}$

Dessa forma, para superar a ideologia que cerca o agronegócio, é crucial desvendar esses mitos associados a ele, pois só assim será possível ultrapassar uma série de entraves que o sustentam e refletir sobre as possibilidades de superação de sua economia e de sua sociedade.

Inspirados no conteúdo e no título do artigo de Ermínia Maricato (2008) - "O nó da terra" -, adotamos a metáfora: os mitos associados ao agronegócio brasileiro são verdadeiros nós que devem ser desatados para podermos seguir um caminho de construção de uma sociedade mais democrática no país. Em seguida, apresentamos o nó da relação orgânica entre o Estado e agentes do agronegócio e o nó da criminalização dos movimentos sociais.

\section{O nó da relação orgânica entre o Estado e agentes do agronegócio}

Um dos nós mais apertados a sustentar o agronegócio brasileiro é o da relação orgânica entre o Estado e agentes do agronegócio. $\bigcirc$ Estado é um dos principais pilares das transformações da atividade agropecuária e do espaço rural brasileiro, que culminaram no modelo de produção denominado agronegócio. Isso desde o Estado intervencionista do período da ditadura militar (1964-1985) até o modelo neoliberal a partir dos anos 1990 ou da inflexão ultraliberal (Ribeiro, 2020) hoje dominante. Em todo esse longo período, o Estado é submisso aos agentes hegemônicos do agronegócio, e isso reforçou o patrimonialismo que historicamente caracteriza a sociedade brasileira e, no caso presente, a relação intrínseca entre poder econômico do agronegócio e poder político.

Um dos signos dessa realidade é a força da FPA, a principal face institucional da BR, uma das maiores e mais organizadas do Congresso Nacional do Brasil, que contabiliza cerca de 250 componentes, entre deputados e senadores. "É também uma das mais conservadoras,

9 De acordo com pesquisa conduzida pela ONG Repórteres Sem Fronteiras e pelo Coletivo Intervozes sobre a concentração midiática no Brasil, os membros da família Marinho que controlam o grupo Globo são donos de fazendas e empresas de produção agrícola. Têm ainda negócios no mercado imobiliário, no setor de finanças e de vendas. Isso faz com que a familia esteja entre as que detêm as maiores fortunas do país (Vilela, 2018).

10 Sobre o tema do agronegócio e da indústria cultural ver Chã (2018), Nobrega e Bandeira (2019) e Santos, A., Silva, D. e Maciel (2019).

11 Após as eleições de 2018, uma reconfiguração da FPA tornou-a mais poderosa e também mais fisiológica, somando 225 deputados federais e 32 senadores em sua base. A lista completa de seus componentes com os partidos aos quais pertencem está disponível em Bassi (2019). 
poderosas e estruturadas em termos de financiamento entre as existentes. ${ }^{12}$ Para citar um exemplo recente, lembramos seu importante papel como base de sustentação do governo ilegítimo de Michel Temer, uma vez que compôs cerca de $50 \%$ dos votos para o processo de impeachment da presidenta Dilma Rousseff (01/01/2011-31/08/2016), assim como para rejeitar as denúncias que tramitavam contra Temer, em meados de 2017. ${ }^{13}$

$O$ poder da FPA vem crescendo e, em parte, isso se deve ao apoio dado aos governos desde o golpe. Por esse motivo, seus membros vêm ocupando postos-chave no legislativo, como comissões parlamentares de peso para o agronegócio, e no executivo (secretarias e ministérios). A estratégia vem sendo utilizada para aprovar leis que anulam direitos sociais e trabalhistas, promovem destruição ambiental, acobertam o trabalho escravo, retardam ou impedem a demarcação de terras indígenas e quilombolas, entre tantas outras usurpações, impondo vários retrocessos.

Entre as maiores evidências do poder da FPA, está a indicação de seus representantes para o cargo máximo atinente ao setor, qual seja, o de ministro da Agricultura, Pecuária e Abastecimento. Para ficar apenas nos dois últimos ministros desde a posse de Michel Temer, citamos Blairo Maggi, indicado pelo ex-presidente e que permaneceu durante a maior parte de seu mandato, e Tereza Cristina Correa da Costa Dias, ministra nomeada pelo presidente Jair Bolsonaro. Vale uma breve apresentação dos respectivos currículos, para não deixar nenhuma dúvida sobre o patrimonialismo que rege o Brasil, aqui caracterizado pela FPA.

Blairo Maggi é um dos maiores produtores de soja do mundo e representantes do agronegócio brasileiro. É o braço político de uma importante corporação, o grupo André Maggi (Amaggi), com sede em Cuiabá (MT) e que, de acordo com informações do próprio site da corporação, controla quatro divisões de empresas ligadas ao agronegócio. Atua no plantio, no processamento e no comércio de grãos, na produção de sementes, na pecuária, na venda de fertilizantes, na geração de energia elétrica, na administração portuária, no transporte fluvial e na exportação e importação, entre outros..$^{14}$

O primeiro mandato de Blairo Maggi foi em 1994, como primeiro suplente do senador Jonas Pinheiro (PFL/MT). Foi eleito governador do Mato Grosso em 2002 e reeleito em 2006. Em 2011, elege-se senador, tendo deixado o cargo em maio de 2016 para assumir o Ministério da Agricultura, Pecuária e Abastecimento (Mapa) (05/2016-31/12/2018) (Craide, 2016). É hoje uma das principais fortunas do Brasil, tendo em 2015 integrado a lista dos bilionários da revista Forbes (Petroli, 2015). ${ }^{15}$

12 Os recursos financeiros para a manutenção da FPA vêm do Instituto Pensar Agro (IPA), criado em 2011. Estes, por sua vez, vêm de um conjunto de grandes empresas e associações diretamente ligadas ao agronegócio, nacionais e multinacionais, assim como de outros setores como bancos, entre as quais estão a Associação dos Produtores de Soja (Aprosoja Brasil), a União da Indústria de Cana de Açúcar (Única) e empresas como Bayer, Basf, BRF, JBS, Bunge, Syngenta, Cargill, entre outras (Arroio, 2019).

13 Eram várias as denúncias de envolvimento de Michel Temer em esquemas de corrupção. Entre os inquéritos no Supremo Tribunal Federal (STF), podemos citar os mais divulgados na grande mídia, especialmente os associados à cobrança de propina de empresas atuantes no porto de Santos (SP) e à JBS, uma das principais corporações do agronegócio. Uma matéria publicada no site da UOL em 2019 cita que, ao todo, o emedebista era alvo de 10 inquéritos espalhados por Brasilia, Rio de Janeiro e São Paulo e já havia sido denunciado três vezes pelo Ministério Público Federal (MPF) (Shalders, 2019).

14 Para informações mais detalhadas sobre a corporação, ver Amaggi ([s.d.]). Para uma leitura geográfica, ver Silva, C. (2011).

15 Dados do Jornal Contábil incluem Blairo Maggi entre as oito maiores fortunas entre os políticos brasileiros (Spigariol, 2018). 
Também conhecido como "rei da soja", a trajetória de Blairo Maggi é um bom exemplo de como o sincretismo entre o público e o privado pode ser bastante lucrativo, uma vez que em poucas décadas teve seu patrimônio multiplicado algumas vezes e hoje é proprietário de uma das principais corporações do agronegócio. Isso não se deu sem custos, por exemplo, para o meio ambiente, uma vez que seus negócios levaram ao desmatamento em larga escala na Amazônia Legal, acabaram com a demarcação de terras indígenas e propiciaram projetos de infraestrutura potencialmente nocivos à biodiversidade. Por essas e por outras razões, já foi apontado por ONG atuantes em questões ambientais, como "inimigo número 1 do meio ambiente". Em 2005, foi agraciado com o nada honroso troféu "motosserra de ouro" do Greenpeace, por sua significativa participação na devastação da floresta amazônica. ${ }^{16}$

Tereza Cristina, por sua vez, não é detentora de fortuna ou corporação comparável à de Blairo Maggi, mas tem extensa ficha de serviços prestados ao agronegócio brasileiro como deputada federal, eleita pela primeira vez em 2015, membro da FPA e agora ministra da Agricultura. Era presidenta da FPA e líder da bancada na Câmara dos Deputados do Brasil quando foi indicada para o cargo de ministra. De familia de pecuaristas com atuação na política no Mato Grosso do Sul (neta e bisneta de ex-governadores do estado), ela própria já tinha atuado como secretária estadual de Desenvolvimento Agrário (Sampaio, 2018), além de já ter ocupado o cargo de gerente-executiva em quatro secretarias: Planejamento, Agricultura, Indústria, Comércio e Turismo. Também exerceu os cargos de diretora-presidente da Agência Estadual de Defesa Sanitária Animal e diretora-presidente da Empresa de Gestão de Recursos Minerais (Pedrozo, 2020).

Mais conhecida como "musa do veneno", por sua posição favorável à aprovação do Projeto de Lei n. 6.299/2002 (PL do veneno), que flexibiliza as regras de utilização de agrotóxicos, assumiu o ministério defendendo essa e outras bandeiras correlatas. ${ }^{17}$ Além da regulamentação para o uso de novos venenos, está prevista até mesmo a mudança do termo agrotóxico, presente na legislação desde 1989, para defensivos fitossanitários ou pesticidas. Várias instituições se manifestaram contrárias às mudanças, como o Ministério da Saúde, a Agência Nacional de Vigilância Sanitária (Anvisa), o Instituto Brasileiro do Meio Ambiente (lbama), o Ministério Público Federal, a Fundação Oswaldo Cruz (Fiocruz), o Instituto Nacional do Câncer (Inca), além de inúmeras organizações da sociedade civil (Quem é Tereza Cristina..., 2018).

Ademais da bandeira pela liberação geral dos agrotóxicos, a atuação de Tereza Cristina à frente do Mapa vem contribuindo direta ou indiretamente para vários outros retrocessos, alguns promovidos pelo próprio Ministério do Meio Ambiente, como a flexibilização das normas para licenciamento ambiental, a diminuição da fiscalização de instituições atuantes na proteção do meio ambiente, como o lbama, e a suspensão da demarcação de terras indígenas, entre outros, comprometendo imediatamente alguns processos positivos que vinham em curso na última década, como a demarcação de terras de povos originários. Por outro lado, impactando gravemente o alarmante desmatamento no país, que vem batendo todos os recordes desde 2019.

16 Para saber mais sobre a trajetória de Blairo Maggi, a formação da corporação controlada por ele e pela familia, assim como sobre sua estreita relação com o Estado, ver Gonzáles (2018).

17 Matéria do Repórter Brasil mostra a relação de empresários ligados aos agrotóxicos no financiamento da campanha de Tereza Cristina para deputada federal (Camargos, 2018). 
Vale destacar que, após as declarações nefastas do ministro do Meio Ambiente Ricardo Salles para "passar a boiada", enquanto organizações ambientalistas de todo o país se manifestavam pedindo a saída do ministro, ${ }^{18}$ financiadores da FPA publicaram anúncio pago de página inteira em jornais impressos de grande circulação - como a Folha de S.Paulo, O Estado de S.Paulo e O Globo - em apoio às políticas do ministro, mas sem citá-lo nominalmente (Entidades empresariais..., 2020; "No meio ambiente..., 2020). Com o título de No meio ambiente, a burocracia também devasta, o manifesto defende a desburocratização como aliada à preservação ambiental. Entre os signatários do manifesto, estão alguns dos principais financiadores do Instituto Pensar Agro (IPA), que sustenta a FPA. A lista era longa, com 88 apoiadores, e, além de entidades diretamente relacionadas com o agronegócio, continha também representantes de empreiteiras e do mercado imobiliário, entre outros. ${ }^{19}$

Para completar as evidências do nó da relação orgânica entre o Estado e agentes do agronegócio, apresentamos dois mapas bastante didáticos e esclarecedores. Um apresenta a produção de soja no Brasil no ano de 2015 (Figura 1), produzido pelo IBGE (2015), e o outro, os dados da votação para presidente, produzido pelo Observatório das Eleições, logo após o final do primeiro turno (Figura 2) (Veja o mapa..., 2018). Os mapas revelam a estarrecedora relação espacial entre as duas principais variáveis utilizadas, quais sejam, a área plantada com soja e o número de votos para o então candidato a presidente Jair Bolsonaro. $\bigcirc$ resultado é um indicador da força que o agronegócio representou para a eleição do atual presidente, caso alguém ainda tivesse dúvidas. Foi nas áreas onde predomina a produção de soja no Brasil, um dos signos maiores do agronegócio no país, que o hoje presidente Jair Bolsonaro obteve a maioria dos votos.

\section{Figura 1 - Brasil: produção de soja nos dez municípios que mais produzem $-2015$}

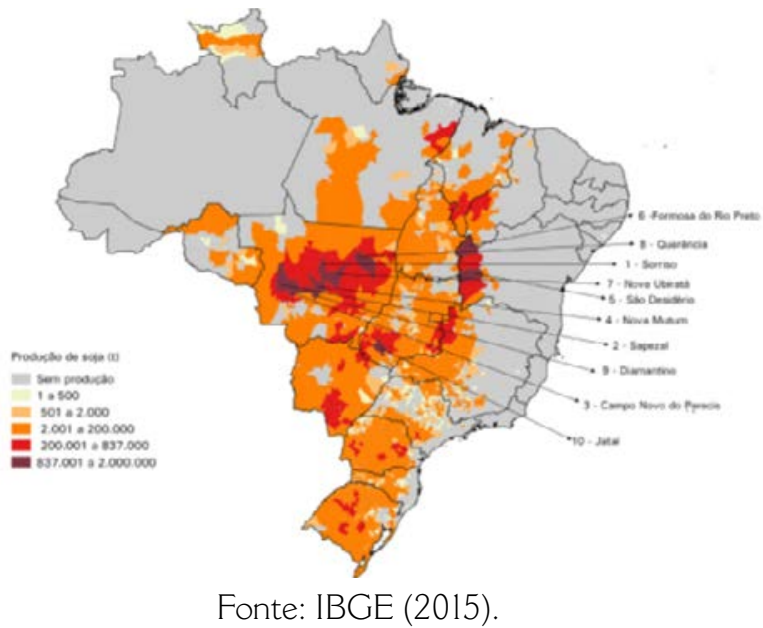

18 Tais como o Greenpeace e o Observatório do Clima, entre outros.

19 A título de exemplo, citamos a Confederação Nacional da Agricultura (CNA), a Associação dos Produtores de Soja (Aprosoja Brasil), a Associação Brasileira dos Produtores e Exportadores de Frutas e Derivados (Abrafrutas), a Associação das Empresas Cerealistas do Brasil (Acebra), a Federação dos Plantadores de Cana do Brasil (Feplana), a Associação Brasileira de Frigoríficos (Abrafrigo), a Confederação Nacional da Indústria (CNI), a Câmara Brasileira da Indústria da Construção (CBIC), a Associação das Administradoras de Bens Imóveis e Condomínios de São Paulo (AABIC), a Associação Brasileira de Incorporadoras Imobiliárias (Abrainc), o Sindicato da Indústria da Construção do Estado de Alagoas (Sinduscon-AL), a Associação Comercial de São Paulo (ACSP) e a Associação Brasileira de Lojistas de Shopping (Alshop) (Castilho, 2020). 


\section{Figura 2 - Brasil: votação para presidente com $98,3 \%$ das urnas apuradas $-2018$}

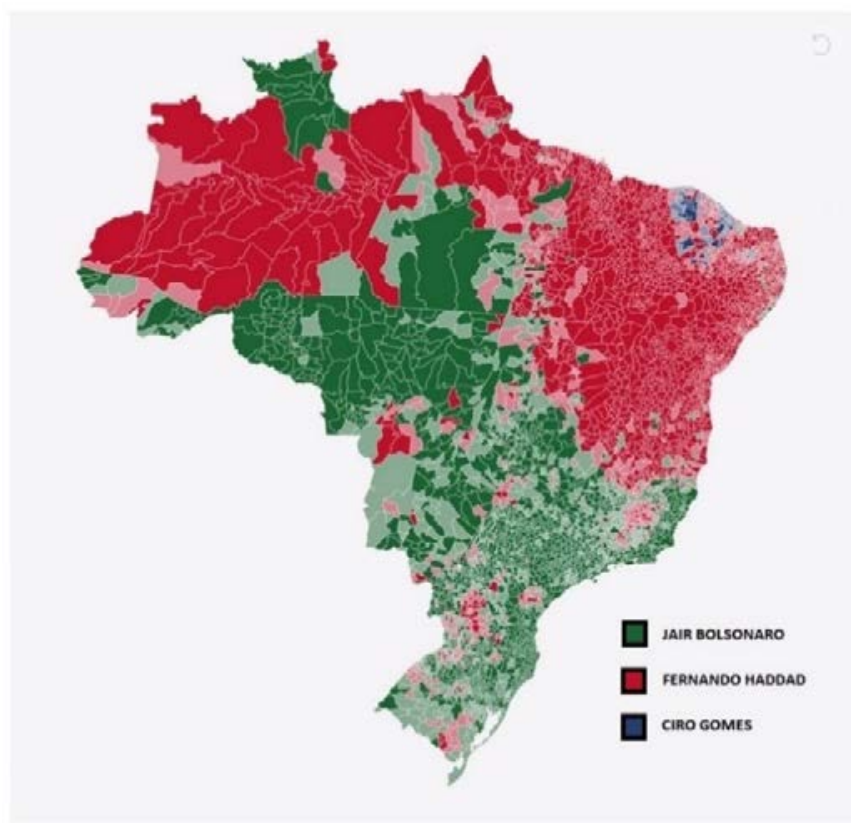

Fonte: Veja o mapa... (2018).

\section{O nó da criminalização dos movimentos sociais}

A criminalização dos movimentos sociais é outro nó que ficou mais apertado desde o golpe parlamentar de 2016. Vivemos um momento de extrema ofensiva conservadora da direita e da extrema direita, empenhadas em criminalizar e intimidar todos aqueles que lutam por um Brasil justo e soberano. Atos de violência e ódio vêm sendo propagados intensamente nas redes sociais e reverberam fortemente em várias instâncias. É mais uma demonstração da violência dos setores da elite econômica e política brasileira dispostos a promover uma onda de abuso e ódio à população mais pobre.

A cada dia temos notícias que demonstram intolerância contra movimentos populares, migrantes, população negra, LGBTQI+ etc., cenário no qual a ilegalidade e a falta de ética são mais regra do que exceção, por parte do judiciário, da polícia e da mídia. Parte da mídia criminaliza os movimentos populares (do campo, indígenas etc.), criando um clima que legitima a repressão policial e das milícias armadas no campo e na cidade.

Alguns expoentes deste momento de retrocesso político se sentem à vontade para destilar sua verborragia criminosa para atacar as comunidades indígenas, quilombolas, trabalhadores agrícolas sem-terra e pessoas trans. Defendem em público, sem nenhum constrangimento, acabar com reservas indígenas e quilombos. Em parte, usam a normatização oficial, sobretudo ao tentar aprovar projetos de lei como o que visa enquadrar os movimentos sociais na Lei Antiterrorismo, aprovada em 2016, por ocasião das Olimpíadas no Rio de Janeiro. Tramita na Câmara dos Deputados o Projeto de Lei n. 5.065/2016, que tipifica atos de terrorismo por motivação ideológica, política, 
social e criminal. Quase uma permissão para o enquadramento de movimentos sociais e manifestantes de modo geral, que poderiam ser tachados como terroristas. ${ }^{20}$

Infelizmente, esse PL é apenas um dos que estão em tramitação no Congresso Nacional e que têm como mote o "combate ao terrorismo". Efetivamente, há um conjunto de projetos de mesma natureza tramitando, liderados por aliados do governo Jair Bolsonaro e que visam cercear direitos da população não alinhada a ele. Entre as propostas, há inclusive a legalização da infiltração de agentes do Estado e o monitoramento telefônico e digital de grupos considerados suspeitos de "atos terroristas". Ainda mais preocupante é o fato de que alguns PL podem ser aprovados diretamente em comissões das casas legislativas, sem passar por votação em plenário. ${ }^{21}$

Não podemos deixar de fazer o paralelo da tramitação desses PL com as declarações no mínimo desastrosas do atual ministro da Economia Paulo Guedes (01/01/2018-) e o deputado federal Eduardo Bolsonaro (PSL-SP, 2015-), no segundo semestre de 2019, por ocasião de manifestações populares de rua no Brasil, sobre a possibilidade de recriar um "novo Ato Institucional número 5". Essas declarações foram amplamente divulgadas pela grande mídia em geral. Aos mais jovens e àqueles que estão inebriados com o governo à frente do executivo federal, lembramos que o Al-5 foi um dos mais perversos do período da ditadura militar brasileira.

Promulgado em 1968, vigorou por dez anos e foi responsável por uma gama de ações arbitrárias. Revogou direitos fundamentais, possibilitando a tortura, a censura a meios de comunicação, a intervenção do governo federal em estados e municípios, a cassação de mandatos de parlamentares e o fim do habeas corpus, entre outros. Em outras palavras, dava aos militares poder de exceção para perseguir e punir os que eram considerados inimigos do regime. ${ }^{22}$

Essa situação é muito preocupante, e a aprovação de um ou de alguns desses PL representará um enorme retrocesso no direito de livre manifestação do cidadão brasileiro. A título de exemplo, considerando o teor de tais PL, o Movimento dos Trabalhadores Rurais Sem-Terra (MST) e o Movimento dos Trabalhadores Sem-Teto (MTST), por exemplo, poderiam ser classificados como grupos terroristas. Por isso incluímos o nó da criminalização dos movimentos sociais como um dos imprescindíveis a ser desatado para a construção de uma sociedade mais plural.

\section{Considerações finais}

Diante do exposto, é fato que vivemos uma democracia rasurada no Brasil desde o golpe de 2016, que se agravou ainda mais com as eleições de 2018, processos que contaram com o apoio dos agentes do agronegócio.

20 A autoria do PLé do deputado Delegado Edson Moreira (PR-MG). Uma consulta ao site da Câmara dos Deputados em novembro de 2020 mostrou que o projeto de lei estava aguardando parecer do relator na Comissão de Segurança Pública e Combate ao Crime Organizado (CSPCCO) (Brasil, 2016).

21 informativo Independente fez um levantamento desses PL e somou 20 iniciativas de aliados bolsonaristas com objetivos próximos e complementares. A matéria também indica cada um deles segundo seu autor, além do principal objetivo, assim como o número do PL, o que permite aos interessados acessarem a página da Câmara dos Deputados e saber mais detalhes, incluindo sobre a situação da tramitação (Bruza, 2019).

22 As falas do ministro da Economia e do deputado federal suscitaram um conjunto de publicações nas mídias oficiais e alternativas sobre do AI-5. Entre elas, citamos a webstorie da Folha de S.Paulo (2020) e as reportagens do Brasil de Fato (Sudré, 2019) e do El País (Betim, 2019). 
O resultado de cinco décadas de privilégios concedidos aos setores do agronegócio no Brasil são o agravamento da concentração fundiária, a expulsão e expropriação de vários povos originários, com a eliminação de muitos saberes e fazeres historicamente construídos, a expansão de monoculturas, com a devastação ambiental e a diminuição da biodiversidade, com um avassalador processo de erosão genética, a difusão de especializações territoriais produtivas, com incremento da urbanização corporativa e reorganização urbano-regional, formação de regiões produtivas compostas por campo e cidades extremamente funcionais para o agronegócio, que revelam novas faces da pobreza estrutural.

Por outro lado, durante a pandemia de Covid-19, ainda em vigência, enquanto o agronegócio e suas mídias ostentam novos recordes de produção, produtividade e volume de exportação de commodities brasileiras, cresceu sensivelmente o número de pessoas sem acesso a alimentação, recolocando o Brasil no Mapa da Fome, do qual havia saído em 2014. Isso desmente outro mito associado ao agronegócio, qual seja, o de que acabaria com a fome no país.

Assim, as formas-conteúdo (Santos, M., 1996) do agronegócio não só podem como devem ser rejeitadas e substituídas por outras. Em caso contrário, não será possível construir um país mais democrático e menos desigual.

\section{Referências}

A HEGEMONIA da concentração sem limites. Media Ownership Monitor Brasil. Disponível em: https://brazil.mom-rsf.org/br/proprietarios/empresas/detail/company/ company/show/grupo-globo/. Acesso em: 9 fev. 2021.

AMAGGI. Disponível em: https://www.amaggi.com.br/. Acesso em: 16 nov. 2020.

ARROYO, P. Multinacionais são financiadoras ocultas da Frente Parlamentar da Agropecuária. De Olho nos Ruralistas - Observatório do Agronegócio no Brasil, 21 maio 2019. Disponível em: https://deolhonosruralistas.com.br/2019/05/21/multinacionais-saofinanciadoras-ocultas-da-frente-parlamentar-da-agropecuaria/. Acesso em: 19 nov. 2020.

BASSI, B. S. Nova Frente Parlamentar da Agropecuária reúne 257 deputados e senadores; com 25, PSL de Bolsonaro só fica atrás de PP e PSD. De olho nos ruralistas Observatório do Agronegócio no Brasil, 22 mar. 2019. Disponível em: https:// deolhonosruralistas.com.br/2019/03/22/nova-frente-parlamentar-da-agropecuariareune-257-deputados-e-senadores-com-25-psl-de-bolsonaro-so-fica-atras-de-pp-e-psd/. Acesso em: 10 fev. 2021.

BETIM, F. O que significou o AI-5 para o Brasil, segundo o historiador Carlos Fico. E1 País, São Paulo, 26 nov. 2019. Disponível em: https://brasil.elpais.com/brasil/2019/11/26/ politica/1574785901_729738.html. Acesso em: 19 nov. 2020.

BRASIL. Câmara dos Deputados. Projeto de Lei n. 5.065, 2016. Altera o artigo $2 \circ$ da Lei n. 13.260/2016, dando nova redação ao seu caput e ao seu $\S 1$, inciso $V$, acrescendo os incisos VI, VII e VIII ao seu $\S 1 \circ$, e revogando o seu $§ 2^{\circ}$. Tipifica atos de terrorismo por motivação ideológica, política, social e criminal. Disponível em: https://www.camara.leg. br/proposicoesWeb/fichadetramitacao?idProposicao=2082470. Acesso em: 19 nov. 2020. 
BRUZA, R. Aliados de Bolsonaro promovem 20 projetos autoritários no Congresso alegando combater o "terrorismo". Independente - Jornalismo Alternativo, 20 dez. 2019. Disponivel em: http://www.independente.jor.br/aliados-de-bolsonaro-promovem-20-projetos -autoritarios-no-congresso-alegando-combater-o-terrorismo/. Acesso em: 19 nov. 2020.

CAMARGOS, D. "Musa do veneno", deputada Tereza Cristina recebe doações de empresários ligados a agrotóxicos. Repórter Brasil, 26 set. 2018. Disponível em: https:// reporterbrasil.org.br/2018/09/musa-do-veneno-deputada-tereza-cristina-recebedoacoes-de-empresarios-ligados-a-agrotoxicos/. Acesso em: 18 nov. 2020.

CASTILHO, A. L. Financiadores da bancada ruralista publicam anúncio em "total apoio" a Ricardo Salles. De Olho nos Ruralistas - Observatório do Agronegócio no Brasil, 26 maio 2020. Disponível em: https://deolhonosruralistas.com.br/2020/05/26/ financiadores-da-bancada-ruralista-publicam-anuncio-em-total-apoio-a-ricardo-salles/. Acesso em: 19 nov. 2020.

$\mathrm{CHÃ}, \mathrm{A}$. M. Agronegócio e indústria cultural: estratégias das empresas para a construção da hegemonia. São Paulo: Expressão Popular, 2018.

CHAUÍ, M. O que é ideologia. 3. ed. São Paulo: Brasiliense, 1981.

CORRÊA, R. L. Metrópoles, corporações e espaço. In: CASTRO, I. E.; GOMES, P. C. C.; CORREAA, R. L. (org.). Brasil: questões atuais da reorganização do território. 2. ed. Rio de Janeiro: Bertrand, 2002. p. 67-114.

CRAIDE, S. Ministro da Agricultura, Maggi é um dos maiores produtores de soja do país. Agência Brasil, Brasilia, DF, 12 maio 2016. Política. Disponível em: https://agenciabrasil. ebc.com.br/politica/noticia/2016-05/ministro-da-agricultura-maggi-e-um-dos-maioresprodutores-de-soja-do-pais. Acesso em: 15 fev. 2021.

DEBORD, Guy. A sociedade do espetáculo. 2003. Disponível em: http://www. ebooksbrasil.org/adobeebook/socespetaculo.pdf. Acesso em: 15 nov. 2020.

DOWBOR, L. A era do capital improdutivo. São Paulo: Autonomia Literária, 2017.

ELIAS, D. O CNPq na conjuntura atual: relato de experiência como representante de área. Geosul, Florianópolis, v. 35, n. 75, p. 735-753, 2020a. doi: https://doi. org/10.5007/1982-5153.2020v35n75p735.

ELIAS, D. A Região Metropolitana como recorte espacial para estudos sobre o agronegócio: questões de método e metodologia. Boletim Goiano de Geografia, Goiânia, v. 40, n. 1, p. 1-28, 2020b. doi: https://doi.org/10.5216/bgg.v40i01.63448.

ELIAS, D. Agronegócio globalizado: do campo a metrópole. In: FERREIRA, A.; RUA, J.; MATTOS, R. C. (org.). O espaço e a metropolização: cotidiano e ação. Rio de Janeiro: Consequência, 2017a. p. 587-509.

ELIAS, D. Construindo a noção de Região produtiva do agronegócio. In: OLIVEIRA, H. C. M.; CALIXTO, M. J. M. S.; SOARES, B. R. (org.). Cidades médias e região. São Paulo: Cultura Acadêmica, 2017b. p. 19-56. 
ELIAS, D. Globalização, agricultura e urbanização no Brasil. Acta Geográfica, Boa Vista, v. 1, p. 13-32, nov. 2013. doi: https://doi.org/10.5654/actageo2013.0003.0001.

ELIAS, D. Ensaios sobre os espaços agrícolas de exclusão. Revista Nera, Presidente Prudente, SP: Unesp, v. 1, n. 8, p. 29-51, 2006. doi: https://doi.org/10.47946/rnera.v0i8.1442.

ELIAS, D. Globalização e agricultura. São Paulo: Edusp, 2003.

ELIAS, D. Integração competitiva do semiárido cearense. In: ELIAS, D.; FURTADO, J. L. S. (org.). Modernização excludente. Fortaleza: Demócrito Rocha, 2002. p. 15-43.

ELIAS, D.; PEQUENO, R. (Re)estruturação urbana e desigualdades socioespaciais em região e cidade do agronegócio. Geographia, Niterói, v. 17, n. 35, p. 10-39, 2015. doi: https:// doi.org/10.22409/GEOgraphia2015.v17i35.al3727.

ELIAS, D.; PEQUENO, R. Desigualdades socioespaciais nas cidades do agronegócio. Revista Brasileira de Estudos Urbanos e Regionais, v. 9, n. 1, p. 25-39, 2007. doi: https:// doi.org/10.22296/2317-1529.2007v9nlp25.

ENTIDADES EMPRESARIAIS apoiam ministro e criticam lei ambiental burocrática... Veja mais em https://economia.uol.com.br/noticias/redacao/2020/05/26/entidadesdesburocratizacao-meio-ambiente.htm?cmpid=copiaecola

FARINA, E. M. M. Q.; ZYLBERSZTAJN, D. (coord.). Competitividade no agribusiness Brasileiro. São Paulo: Pensa/FIA/FEA-USP, 1998.

FOLHA DE S.PAULO. Webstorie. 2020. Disponível em: https://wwwl.folha.uol.com.br/ webstories/cultura/2020/07/o-que-foi-o-ai-5/. Acesso em: 19 nov. 2020.

GOOGLE. Disponível em: https://www.google.com/search?q=quantos+mortos+no+ mundo+hoje+pela+pandemia +do+coronav\%C3\%ADrus Eoq=quantos+mortos+no+ mundo + hoje+pela + pandemia + do + coronav\%C3\%ADrus $E$ aqs $=$ chrome. .69i57j33i22i 29i30.11470j0j15E-sourceid=chromeE-ie=UTF-8. Acesso em: 9 fev. 2021.

GONZALES, J. Críticos afirmam: Blairo Maggi, o rei da soja, reina absoluto sobre o destino da Amazônia. Mongabay, 9 jul. 2018. Disponível em: https://brasil.mongabay. com/2018/07/criticos-afirmam-blairo-maggi-rei-da-soja-reina-absoluto-destino-daamazonia/. Acesso em: 16 nov. 2020.

GRUPO GLOBO. Media Ownership Monitor Brasil. Disponível em: https://brazil.momrsf.org/br/proprietarios/empresas/detail/company/company/show/grupo-globo/. Acesso em: 9 fev. 2021.

IBGE. INSTITUTO BRASILEIRO DE GEOGRAFIA E ESTATÍSTICA. Produção agrícola municipal: culturas temporárias e permanentes. Rio de Janeiro: IBGE, 2015.

MARICATO, E. O nó da terra. EcoDebate, 14 jul. 2008. Disponível em: https://www. ecodebate.com.br/2008/07/14/o-no-da-terra-artigo-de-erminia-maricato/. Acesso em: 19 jun. 2017.

MAZZALI, L. O processo recente de reorganização agroindustrial: do complexo à organização em rede. São Paulo: Ed: Unesp, 2000. 
MINISTRO CELSO DE MELLO autoriza acesso a vídeo de reunião ministerial. Supremo Tribunal Federal, 22 maio 2020. Imprensa. Disponível em: https://portal.stf.jus.br/ noticias/verNoticiaDetalhe.asp?idConteudo=443959Eori=1. Acesso em: 12 nov. 2020.

MINISTRO DO MEIO AMBIENTE defende passar "a boiada" e "mudar" regras enquanto atenção da mídia está voltada para a Covid-19. G1, 22 maio 2020. Política. Disponível em: https:// gl.globo.com/politica/noticia/2020/05/22/ministro-do-meio-ambiente-defende-passar-aboiada-e-mudar-regramento-e-simplificar-normas.ghtml. Acesso em: 24 maio 2021.

MULLER, G. Complexo agroindustrial e modernização agrária. São Paulo: Hucitec/ Educ, 1989.

"NO MEIO AMBIENTE, a burocracia também devasta". AgroSaber, 26 maio 2020. Disponível em: https://agrosaber.com.br/no-meio-ambiente-a-burocracia-tambemdevasta/ e https://economia.uol.com.br/noticias/redacao/2020/05/26/entidadesdesburocratizacao-meio-ambiente.htm. Acesso em: 19 nov. 2020.

NOBREGA, C.; BANDEIRA, O. Agronegócio e mídia brasileira: onde duas monoculturas se conectam. Le Monde Diplomatique Brasil, 21 jan. 2019. Disponível em: https:// diplomatique.org.br/agronegocio-e-midia-brasileira-onde-duas-monoculturas-seconectam/. Acesso em: 24 nov. 2020.

OLIVEIRA, A. U. A mundialização da agricultura brasileira. São Paulo: landé, 2016.

PEDROZO, J. Z. Tereza Cristina! Página Rural, 22 abr. 2020. Disponível em: https://www. paginarural.com.br/artigo/3022/tereza-cristina. Acesso em: 20 nov. 2020.

PETROLI, V. Blairo Maggi integra lista dos bilionários da Forbes com fortuna de U\$1,2 bilhão. Olhar Agro $\mathcal{E}$ Negócios, 3 mar. 2015. Disponível em: https://www.agroolhar.com. $\mathrm{br} /$ noticias/exibir.asp?id=18499 Enoticia=blairo-maggi-integra-lista-dos-bilionarios-daforbes-com-fortuna-de-u-12-bilhao. Acesso em 15 nov. 2020.

QUEM É TEREZA CRISTINA, "musa do veneno" confirmada na Agricultura. Carta Capital, 8 nov. 2018. Política. Disponível em: https://www.cartacapital.com.br/ politica/quem-e-tereza-cristina-muda-do-veneno-confirmada-na-agricultura/. Acesso em: 18 nov. 2020.

RIBEIRO, L. C. Q. Inflexão ultraliberal e a financeirização da ordem urbana brasileira: explorando algumas hipóteses. In: RIBEIRO, L. C. Q. As metrópoles e o capitalismo financeirizado. Rio de Janeiro: Letra Capital/Observatório das Metrópoles, 2020. p. 371-418.

SAMPAIO, C. "Musa do veneno": saiba quem é a ministra da Agricultura de Bolsonaro. Brasil de Fato, São Paulo, 9 nov. 2018. Disponível em: https://www.brasildefato.com. br/2018/11/09/musa-do-veneno-saiba-quem-e-a-ministra-da-agicultura-de-bolsonaro/. Acesso em: 10 fev. 2021.

SANTOS, A. D. G.; SILVA, D. V.; MACIEL, K. N. A campanha publicitária 'Agro é tech, agro é pop, agro é tudo', da Rede Globo de Televisão, como difusora da propaganda sobre o agronegócio no Brasil. Revista Eptic, v. 21, n. 1, p. 46-61, jan./abr. 2019. Disponível em: https://seer.ufs.br/index.php/eptic/article/view/10910/8460. Acesso em: 28 maio 2021. 
SANTOS, M. Por uma outra globalização. Rio de Janeiro: Record, 2000.

SANTOS, M. A natureza do espaço: técnica e tempo, razão e emoção. São Paulo: Hucitec, 1996.

SANTOS, M. Técnica, espaço, tempo: globalizacão e meio técnico-científico-informacional. São Paulo: Hucitec, 1994.

SANTOS, M. Metamorfose do espaço habitado. São Paulo: Hucitec, 1988.

SANTOS, M. Espaço e método. São Paulo: Nobel, 1985.

SANTOS, M. O espaço dividido. São Paulo: Edusp, 1979.

SHALDERS, A. Michel Temer preso: conheça detalhes de todas as investigações por corrupção contra o ex-presidente. UOL, 22 mar. 2019. Notícias. Disponível em: https://noticias.uol.com.br/ultimas-noticias/bbc/2019/03/22/michel-temer-presoconheca-detalhes-de-todas-as-investigacoes-por-corrupcao-contra-o-ex-pres. htm?cmpid=copiaecola. Ecmpid=copiaecola. Acesso em: 23 nov. 2020.

SILVA, C. A. F. As redes políticas do grupo Amaggi. Rio de Janeiro: Livre Expressão, 2011. SILVA, J. G. A nova dinâmica da agricultura brasileira. Campinas, SP: IE-Unicamp, 1996.

SORJ, B. Estado e classes sociais na agricultura brasileira. Rio de Janeiro: Zahar, 1980.

SOUZA, O. B. Os impactos da gestão ruralista da Funai. Outras Mídias, São Paulo: ISA, 8 nov. 2019. Disponível em: https://outraspalavras.net/outrasmidias/os-impactos-dagestao-ruralista-da-funai/. Acesso em: 11 nov. 2020.

SPIGARIOL, A. Quais são os 8 políticos mais ricos do Brasil e qual é a origem de suas fortunas. Jornal Contábil, 15 ago. 2018. Disponível em: https://www.jornalcontabil.com.br/ quais-sao-os-8-politicos-mais-ricos-do-brasil-e-qual-e-a-origem-de-suas-fortunas/. Acesso em: 17 fev. 2021.

SUDRÉ, L. Entenda o que foi o Al-5, ato ditatorial defendido por Eduardo Bolsonaro. Brasil de Fato, São Paulo, 31 out. 2019. Disponível em: https://www.brasildefato. com.br/2019/10/31/entenda-o-que-foi-o-ai-5-ato-ditatorial-defendido-por-eduardobolsonaro. Acesso em: 19 nov. 2020.

VEJA O MAPA da votação presidencial por regiões. Carta Capital, 8 out. 2018. Política. Disponível em: https://www.cartacapital.com.br/politica/veja-o-mapa-da-votacao-pormunicipio/. Acesso em: 8 out. 2018.

VILELA, P. R. Do agronegócio ao mercado imobiliário: conheça os outros negócios dos donos da mídia. Brasil de Fato, São Paulo, 2 fev. 2018. Disponível em: https://www.brasildefato. com.br/2018/02/02/do-agronegocio-ao-mercado-imobiliario-conheca-os-outrosnegocios-dos-donos-da-midia. Acesso em: 10 fev. 2021.

Recebido em: 31 ago. 2020 Aprovado em: 27 maio 2021 